\title{
O BATOLITO CALCIO-ALCALINO DE ALTO- K DA SERRA DA LAGOINHA, ESTADOS DO CEARÁ E PARAÍBA: COEXISTÊNCIA E MISTURA DE MAGMAS DIORÍTICOS COM MAGMAS QUARTZO MONZONÍTICOS A GRANÍTICOS
}

\author{
GORKIMARIANO* \& MAURÍCIO DE NASSAU DE MATTOS SOBREIRA**
}

\begin{abstract}
THE HIGH-K CALC-ALKALIC SERRA DA LAGOINHA BATHOLITH, STATES OF CEARÁ AND PARAÍBA: COEXISTENCE AND MIXING OF DIORITIC AND OUARTZ MONZONITIC TO GRANITIC MAGMAS The Serra da Lagoinha batholith (SLB) hás an outcrop área of $200 \mathrm{~km}^{2}$ is located in the Borborema Province, northeastern Brazil, and intrudes schists and phylites at the border of the Cachoeirinha-Salgueiro fold belt. Its southern border is defmed by a major curved NE-SW sinistral transcurrent shear zone (Boqueirão dos Cochos) connecting the E-W dextral shear zones of Patos to the north and Pernambuco to the south. The SLB hás three lithologic domains: the felsic porphyritic domain composed of K-feldspar megacrystic monzonitic, quartz monzonitic, quartz monzodioritic, granitic to granodioritic rocks; the K-dioritic domain composed of biotite (quartz) dioritic to tonalitic rocks and the hybrid domain composed of monzonitic and biotite (quartz) dioritic rocks. Field evidences show that these lithologic domains were produced by the coexistence and mixing of K-diorites with potassic mozonitic to granodioritc magmas. The mafic rocks are enriched in $\mathrm{Nb}, \mathrm{Ba}$, and $\mathrm{Zr}$ and LREE in relation to the felsic porphyritic rocks. The REE patterns for mafic and felsic rocks are similar and enriched in the LREE in relation to the HREE, with $(\mathrm{La} / \mathrm{Yb})_{\mathrm{N}}$ varying from 22.43 to 36.10 for the felsic and from 27.21 to 58.87 for the mafic rocks. $\mathrm{Al}_{\mathrm{T}}$ in amphibole geobarometer (Hollister et al. 1987) shows that amphibole crystallization in the SLB occurred at approximaatelly $4.5 \mathrm{kbar}$. Geothermometry based on the coexistence of amphibole and plagioclase, (Blundy \& Holland 1990) gives a temperature of $742^{\circ} \mathrm{C}$. Whole rock Oxygen isotope data showed average values for mafic of $\delta{ }^{18} \mathrm{O}=+7.9$ permilsmow and for the felsic rocks of $\delta{ }^{18} \mathrm{O}=+9.1$ permilsMOW, suggesting either isotopic equilibrium of coexistent magmas of distinct sources or crystal fractionation process controlling the evolution from mafic to felsic rocks. Quartz corrected values for the felsic pophyritic rocks averaged $\delta^{18} \mathrm{O}$ $=+9.2$ permilsmow, suggesting that the whole rock data represent magmatic values. Sm-Nd sistematics show T(DM) of 1.78 and $1.70 \mathrm{Ga}$ and $\varepsilon_{\mathrm{Nd}}(600)$ of -11.5 and -10.2 for two felsic porphyritic samples and T(DM) of $1.78 \mathrm{Ga}$ and $\varepsilon_{\mathrm{Nd}}(600)$ of -11.15 for a K-diorite. This data may reflect a mixed source rocks formed essentially by Transamazonia (ca $2.0 \mathrm{Ga}$ ) with reduced participation of Caririris Velhos (ca $1.0 \mathrm{Ga}$ ) lithospheric mantle. Major, trace and REE associated with the field evidence support the coexistence and local mixing of K-dioritic with Quartz monzonitic to granitic magmas of distinct sources as the major petrogenetic process for the SLB.

Keywords: High-K calc-alkalic, Itaporanga-type, Magma mixing, Geochemistry, Oxygen Isotopes, NE Brazil.

RESUMO O batólito de Serra da Lagoinha (BSL) com área aflorante de $200 \mathrm{~km}^{2}$ localiza-se na Província Borborema, no nordeste do Brasil, e intrude xistos e filitos na borda do cinturão de dobramentos Cachoeirinha-Salgueiro. O seu limite sul é definido por uma transcorrência sinistrai (Boqueirão dos Cochos) de direção NE-SW que conecta as megatranscorrências dextrais de direção E-W de Patos a norte e de Pernambuco a sul. No BSL foram identificados três domínios litológicos: o félsico porfirítico composto por monzonitos, quartzo monzonitos, quartzo monzodioritos, granitos a granodioritos, com megacristais de K-feldspato ou com granulação grossa; o K-diorito composto por biotita (quartzo) dioritos a tonalitos e o híbrido composto de monzonitos e biotita (quartzo) dioritos. As evidencias de campo mostram que estes domínios litológicos foram produzidos pela coexistência e mistura de magmas de composição diorítica ricos em potássio com magmas de composição quartzo monzonitos a granitos potássicos. As rochas de composiçãoo diorítica são enriquecidas em Nb, Ba, e Zr e TRL em relação às félsicas. Os padrões de ETR para as rochas máficas e félsicas são semelhantes, enriquecidos em TRL em relação aos TRP e com (La/Yb)N variando de 22,43 a 36,10 nas rochas félsicas e de 27,21 a 58,87 nas dioríticas. Geobarômetro baseado em Air em anfibólio (Hollister et al 1987) mostra que a cristalizacão do anfibólio no BSL ocorreu a aproximadamente $4,5 \mathrm{kbar}$. Geotermometria com base na coexistência de anfibólio e plagioclásio, Blundy \& Holland (1990), fornece temperatura em torno de $742^{\circ} \mathrm{C}$. Isótopos de Oxigénio em rocha total mostraram valores médios para as rochas máficas de $\delta \mathrm{O}^{18}=+7,9$ permilsmow e para as rochas félsicas de $\delta \mathrm{O}^{18}=+9,1 \%$ osmow, sugerindo equilíbrio isotópico através da coexistência de magmas de fontes distintas ou processos de cristalização fracionada. Os valores obtidos através da correção por quartzo para as rochas félsicas apresentaram, em média, $\delta \mathrm{O}^{18}=+9,2 \%$ OSMOW., sugerindo que os valores de $\delta \mathrm{O}^{18}$ determinados em rocha total são primários. A sistemática de Sm-Nd mostra T(DM) de 1,78 e 1,70 Ga e $\varepsilon_{\mathrm{Nd}}(600)$ de -1 1,5 e -10,2 para duas amostras félsicas porfiríticas e T(DM) de 1,78 $\mathrm{Ga}$ e $\varepsilon_{\mathrm{Nd}}(600)$ de $-11,15$ para um K-diorito. Isto reflete uma fonte para o BSL formada essencialmente por material do manto litosférico de idade transamazonica (ca 2,0 Ga) com reduzida contribuição de manto litosférico de idade Cariris Velhos (ca 1,0 Ga). Os dados geoquímicos obtidos para elementos maiores, tracos e terras raras para o BSL, associados as evidências de campo, caracterizam diferentes etapas de interação entre os magmas máficos e félsicos, evidenciando a predominância do processo de mistura de magmas de fontes distintas durante a evolução do BSL.

Palavras-chaves: Cálcio-alcalino de alto-K, Tipo Itaporanga, Mistura de magmas, Geoquímica, Isótopos de Oxigénio, Nordeste do Brasil.
\end{abstract}

INTRODUÇÃO Feições de campo que caracterizam a associação entre rochas cálcio alcalinas de alto-K de composição diorítica com rochas cálcio-alcalinas de alto-K de composição quartzo monzonítica a granítica, de textura grossa a porfirítica foram identificadas em vários corpos ígneos de idade Brasiliana e de dimensões batolíticas no Nordeste do Brasil. Esta associação litológica foi inicialmente chamada de granitos do tipo-Itaporanga por Almeida et al. (1967) e como associação do tipo-Itaporanga por Sial et al. (1989). O batólito de Itaporanga, nas proximidades da cidade homónima no estado da Paraíba, foi definido como localidade-tipo dos granitóides do tipo-Itaporanga por Almeida et al (1967) com base essencialmente em critérios petrográficos, tendo sido posteriormente estudado em detalhe por Mariano (1990), Mariano \& Sial (1990) e Mariano et al. (1992). Os batólitos de Bodocó (McMurry 1991) e Fazenda Nova (Neves \& Vauchez 1995) em Pernambuco; o plutão de Acari (Jardim de Sá 1994), no Rio Grande do Norte, e o batólito de Serra da Lagoinha (Sobreira 1995, Sobreira et al. 1993, Mariano 1994), na Paraíba e Ceará, foram, também identificados como membros da associação Itaporanga. Em todos estes batólitos, com ampla distribuição geográfica, é comum a ocorrência de dioritos ricos em $\mathrm{K}_{2} \mathrm{O}$ (a partir daqui denominados de K-dioritos) em forma de diques, bolsões, estruturas venuladas, estruturas do tipo estromáticas, e enclaves de variados formatos associados com rochas de composição quartzo monzonítica a granítica ss., com megacristais de K-feldspato ou de granulação grossa, sugerindo coexistência e, localmente, mistura mecânica entre magmas dioríticos e quartzo monzoníticos a granitos ricos em $\mathrm{K}_{2} \mathrm{O}$.
Neste trabalho serão discutidas feições de campo, petrografia, geoquímica de elementos maiores, traços e terras raras e dados de isótopos de oxigénio e Sm-Nd para o batólito de Serra da Lagoinha que possui $200 \mathrm{~km}^{2}$ de área aflorante e apresenta a litofácies porfirítica como predominante, observando-se além desta as litofácies K-dioritica e híbrida (Sobreira 1995).

O BATÓLITO DE SERRA DA LAGOINHA O batólito de Serra da Lagoinha (BSL) inserido na província da Borborema, intrude metassedimentos do cinturão de dobramentos denominado de PiancóAlto Erigida (Brito Neves 1975) e como Cachoeirinha-Salgueiro por Sial et al (1981a e 1981b). Este cinturão de dobramentos se localiza no domínio Transversal (Ebert 1962, Jardim de Sá 1994), limitado a norte pelo lineamento Patos e a sul pelo lineamento Pernambuco. Dentro do domínio Transversal, Santos (1995) delimitou os terrenos Alto Moxotó e Alto Pajeú e a faixa de dobramentos Piancó-Alto Erigida. Brito Neves et al. (1996), discutindo o evento Cariris Velhos (1.1 a $0.95 \mathrm{Ga}$ ) na Província Borborema, define o sistema Piancó-Alto Brígida como uma área de ocorrência de rochas vulcano-sedimentares de baixo grau intrudidas por granitóides brasilianos. Dentre estes granitóides pode-se destacar os batólitos compostos cálcio-alcalinos de alto-K do tipo-Itaporanga.

Estes granitóides estão comumente associados a zonas de cisaIhamento transcorrentes. As relações temporais de posicionamento dos plutões e a atividade tectônica nas zonas de cisalhamento, de uma maneira geral, carecem de estudos mais detalhados. Devido as dimensões batolíticas destes corpos e as restritas faixas miloníticas observadas no interior dos mesmos, torna-se dificil aceitar que o posiciona-

* Universidade Federal de Pernambuco - Centro de Tecnologia e Geociências - Departamento de Geologia - Recife - PE. 50740-530.

** Pós-graduação em Geociências - Universidade Federal de Pernambuco - Centro de Tecnologia e Geociências -Departamento de Geologia - Recife - PE. 
mento destes tenha sido controlado exclusivamente por zonas de cisalhamento, ou que estas tenham funcionado como condutos para a ascensão magmática. Neves et al (1996) estudando a relação entre zonas de cisalhamento e o posicionamento de granitóides na província Borborema propõem, para alguns casos, a possibilidade da zona de cisalhamento ter sido desenvolvida a partir de heterogeneidade crustal causada pela presença de corpos ígneos em nível crustal, em estágio pre-cristalização. Os principais argumentos para Neves et al. (1996) foram a localização de faixas miloníticas restritas ao interior de alguns corpos graníticos com passagem gradativa para domínios de foliação essencialmente magmática e, comumente, de baixo ângulo; truncamento de foliações magmáticas por zonas de cisalhamento e a deformação insignificante das rochas encaixantes na área de continuação da zona de cisalhamento. Estas observações sugerem que o corpo ígneo exerce um forte controle no desenvolvimento de zonas de cisalhamento.

No BSL, apenas em uma estreita faixa na sua porção SE, ao longo do contato definido pela zona de cisalhamento de Boqueirão dos Cochos, observa-se o desenvolvimento de foliação milonítica. As relações C-S observadas caracterizam o sentido de movimento sinistrai da zona de cisalhamento. No restante do corpo predominam foliações magmáticas, mesmo nas porções onde se observa uma interação íntima entre dioritos e quartzo monzonitos a granitos porfiríticos, ambos ricos em $\mathrm{K}_{2} \mathrm{O}$.

Litofácies do BSL Durante o mapeamento geológico (escala de $1: 70.000)$ do BSL conduzido por Sobreira (1995) foram identificados três litofácies: félsica porfirítica; K-dioritica e híbrida (Fig. 1). Estas litofácies foram identificadas considerando-se a composição mineralógica e química, aspectos texturais, relações de contato e interação entre tipos litológicos.

LITOFÁCIES FÉLSICA PORFIFtÍTICA Esta litofácies, a mais abundante do BSL, ocorre em relevo topográfico positivo. E composta por monzonitos, quartzo monzonitos, quartzo monzodioritos, granodioritos a granitos porfiríticos, com megacristais de K-feldspato com até 10 $\mathrm{cm}$ de comprimento. A matriz é composta por plagioclásio $(59,4$ a 32,3 $\%)$, microclina (52,4 a 16,0 \%), biotita (16,6 a 2,4\%), quartzo $(18,4$ a $32,3 \%$ ), hornblenda $(9,8$ a $1,2 \%)$, opacos, apatita, zircão e allanita $(4,4$ a $0,2 \%)$ e sericita, clorita, calcita e epidoto como minerais de alteração secundária. $\mathrm{O}$ plagioclásio $\left(\mathrm{An}_{27-39}\right)$ ocorre como fenocristal euédrico e na matriz das rochas, apresentando variados graus de sericitização que frequentemente ressaltam a sua zonação composicional. A microclina $\left(\mathrm{Or}_{98}\right)$ desenvolve megacristais euédricos a subédricos, ocorrendo, também, na matriz com cristalização concomitante com o plagioclásio. $\mathrm{O}$ quartzo caracteriza-se por ocupar os espaços intersticiais, desenvolvendo textura mirmequítica na borda de alguns cristais de plagioclásio e frequentemente com extinção ondulante. A biotita ocorre de palhetas de pequena dimensão, associadas aos cristais de hornblenda, em alguns casos como produto da reação daqueles com o líquido. A hornblenda ocorre em cristais subédricos, com dimensão maior em torno de $1,0 \mathrm{~mm}$, sua composição varia de ferro-horblenda a hornblenda ferro-edenítica, de acordo com a classificação de Leake et al. (1997). Entre os acessórios a apatita ocorre em seções basais prismáticas, a titanita como cristais euédricos, frequentemente com núcleo de minerais opacos (magnetita/ilmenita).

LITOFÁCIES K-DIOFÍTICA É composta por dioritos a quartzo dioritos ricos em potássio, também chamado de biotita diorito, ocorre associado ao litofácies félsica porfirítica, sob forma de diques, enclaves elipsoidais e de formato irregular, bolsões e desenvolvendo complexos venulares semelhantes a estruturas estromáticas dos migmatitos, com alternância de bandas centimétricas de dioritos intercalados com quartzo monzonitos a granitos porfiríticos, sugerindo coexistência e mistura de magmas. Suas fases minerais são essencialmente aquelas descritas para a litofácies félsica porfirítica, variando em sua proporção relativa. Plagioclásio, biotita e anfibólio são os minerais mais abundantes. De acordo com a classificação modal de Streckeisen (1976) é composto por dioritos, biotita dioritos a tonalitos. Apatita comumente apresenta hábito acicular, com longas e inúmeras agulhas com a relação largura/comprimento variando de 1:20 a 1:40 (Fig. 2). Esta característica evidencia choque térmico quando da interação deste com o magma félsico.

LITOFÁCIES HÍBRIDA Tem área aflorante restrita a uma estreita faixa na porção sul do batólito, em contato com a zona de cisalhamento sinistrai de Boqueirão dos Cochos (Fig. 1). Possui tipos litológicos que variam de monzonitos, biotita (quartzo) dioritos a monzodioritos. É comum a ocorrência de bordas de reabsorção em várias fases minerais, evidenciando desequilíbrio entre as fases em cristalização e o líquido residual, provavelmente resultado do aumento de temperatura durante a cristalização. Este aumento de temperatura poderia ter sido causado pelo aporte do magma máfico em distintos pulsos ao longo da história de cristalização do batólito. Observa-se, ainda, formação de aglomera-

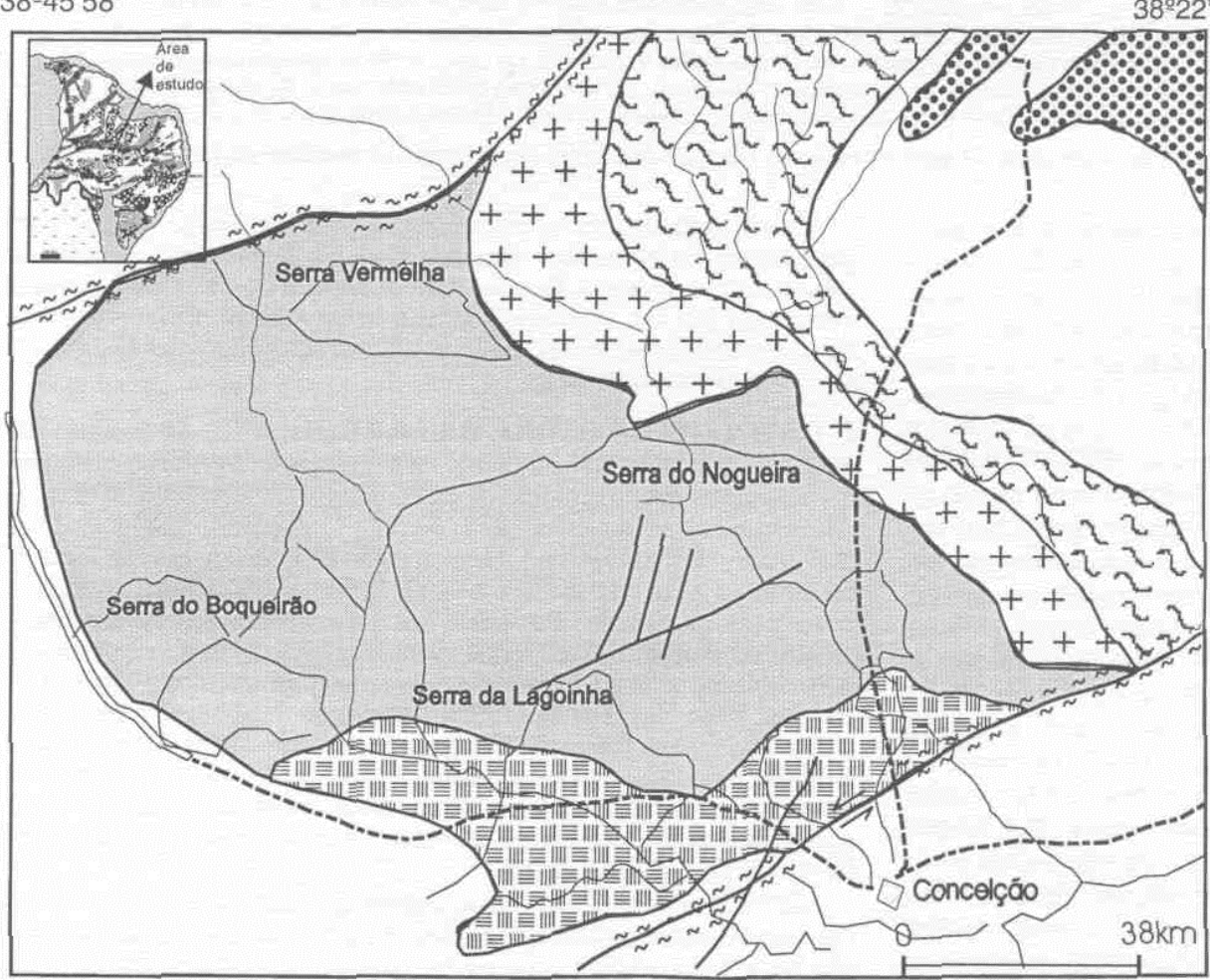

$38^{\circ} 22^{\prime} 05^{\prime \prime}$

Batólito Serra da Lagoinha

Litofacies porfirítica (Quartzo monzonito a granito)

Litofacies hibrida

(Monzonito-monzodiorito-qtzo diorito)

Granito leucocrático fino

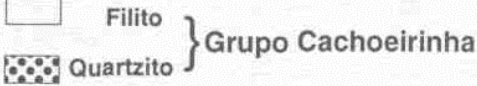

Biotita Xisto - Grupo Salgueiro

\section{Convenções}


dos de cristais de plagioclásio. Hogan (1993) propõem que a desestabilização e reabsorção parcial de cristais de plagioclásio neoformados desenvolve um filme de líquido em torno destes favorecendo a sua união. No BSL alguns cristais de plagioclásio tem contornos irregulares e borda em descontinuidade óptica com o seu centro, devido a sua reabsorção parcial pelo líquido residual. Esta reabsorção pode desenvolver uma película de líquido em volta destes cristais, favorecendo a formação de aglomerados de plagioclásios comuns nesta litofácies.

Evidências de campo de coexistência e mistura de magmas no BSL Na associação do tipo Itaporanga, evidências de campo que fortemente sugerem a coexistência e mistura local de magmas de composição diorítica com magmas de composição quartzo monzonítica a granítica com megacristais de K-feldspato ou granulação grossa, ambos ricos em potássio, já foram descritas para os batólitos de Itaporanga (Mariano 1989); Bodocó (McMurry 1991); Acari (Jardim de Sá 1994) e Fazenda Nova (Neves 1996). No BSL as feições de campo mais interessantes são: estruturas tipo pillow- caracterizadas pela ocorrência de enclaves com formatos irregulares, que sugerem resfriamento rápido do magma máfico em contato com o félsico. Neste tipo de estrutura é comum o desenvolvimento de apatita acicular nucleada na superfície de quase todas as fases minerais (Fig. 2).

(b) recorrência do magmatismo máfico - as interações entre os

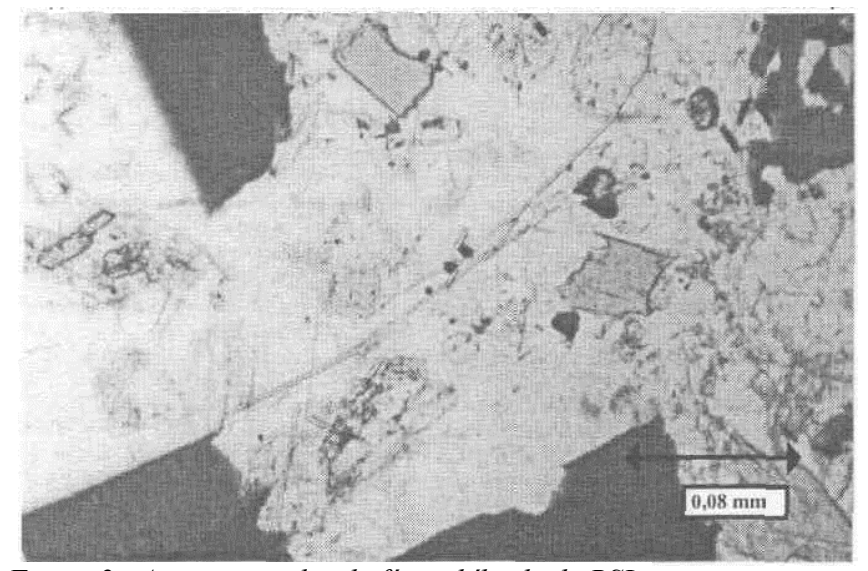

Figura 2 - Apatita acicular da fácies híbrida do BSL.

magmas máfico e félsico observadas no BSL são caracterizadas por

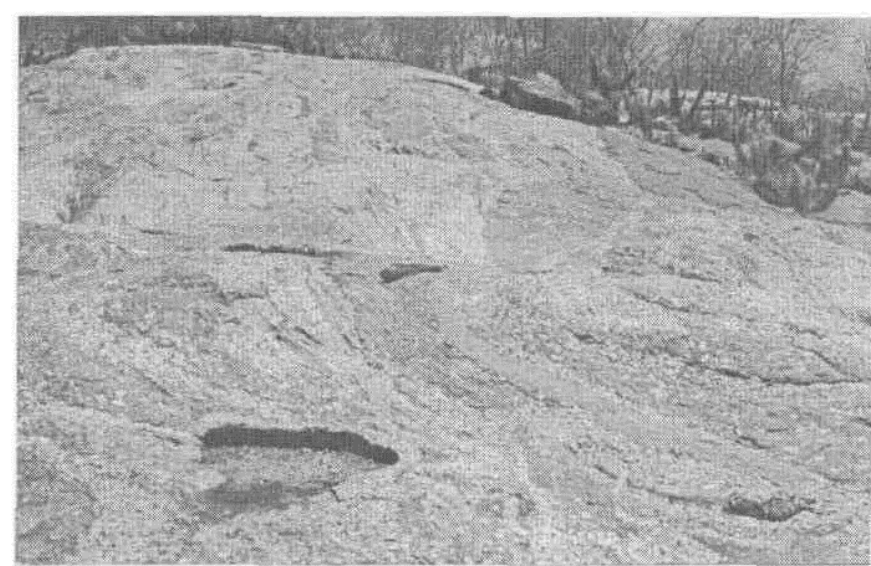

Figura 3 - Complexo venular semelhante a estrutura estromática dos migmatitos, caracterizando forte interação entre magmas máficos e félsicos. Fácies híbrida do BSL.

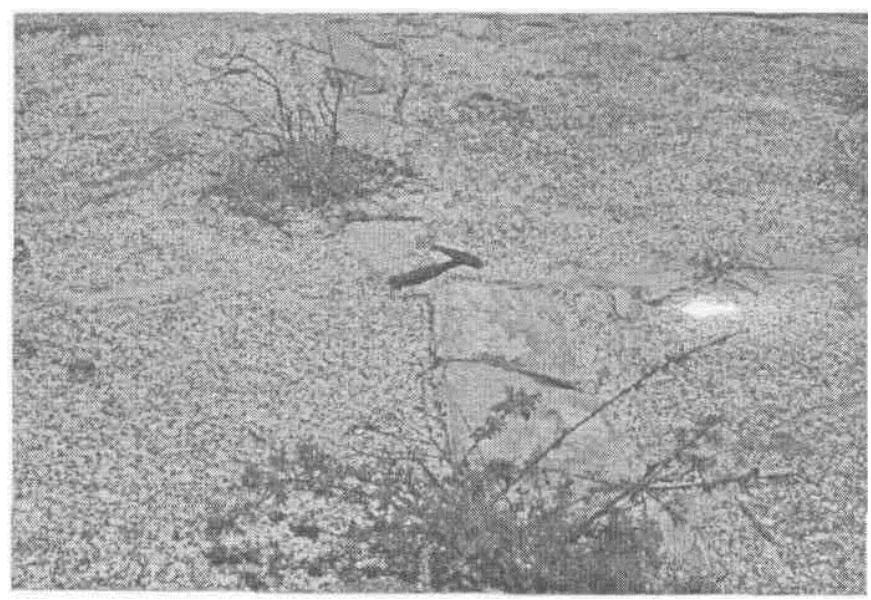

Figura 4- Dique cie rocna diorítica cortando a rocha félsica porfirítica, caracterizando pulso do magmatismo máfico posterior ao félsico. Observa-se a ausência de megacristais de K-feldispato no dique.

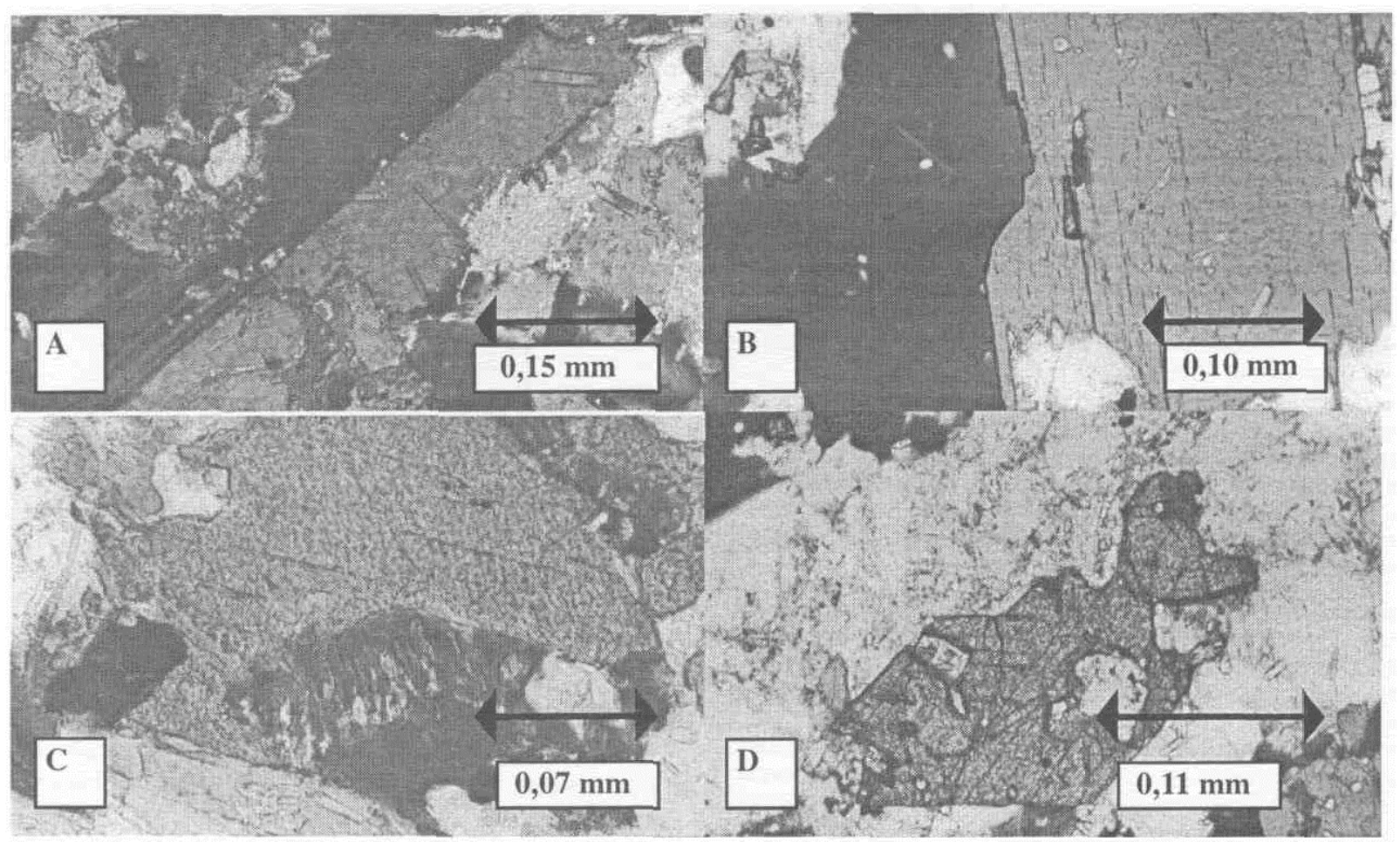

Figura 5 - Bordas de corrosão em: A - plagioclásio; B -biolita; $C$ - anfibólio; D - titanita, caracterizando desequilíbrio térmico durante a cristalização. 


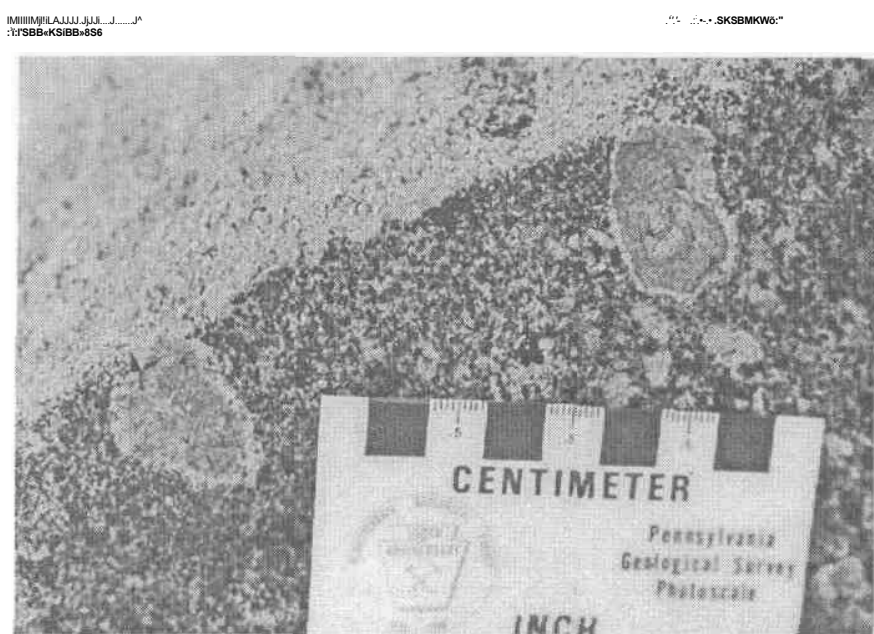

Figura 6 - Textura rapakivi no fácies híbrida do BSL.

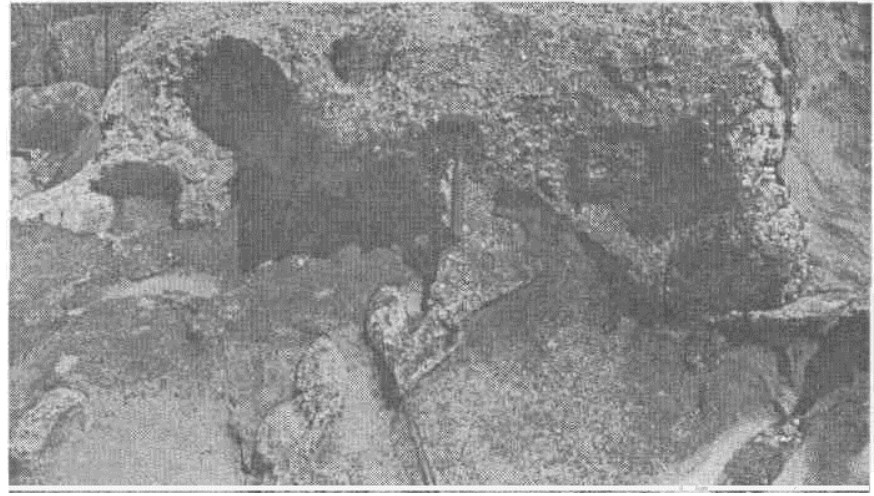

Figura 7 - Relação entre rochas máficas efélsicas, fácies híbrida do BSL, caracterizando aprisionamento do magma máfico sob a câmara magmática preenchida pelo magma félsico.

complexos de veios e diques sinplutônicos, desenvolvendo estruturas semelhante à estrutura estromática dos migmatitos (Fig. 3), onde bandas félsicas porfiríticas se alternam com bandas dioríticas ricas em megacristais de K-feldspato. Não há deformação tectônica associada ao desenvolvimento desta estrutura no BSL. Trata-se de uma feicão exclusivamente ígnea. Diques tardios de K-dioritos cortando rochas félsicas porfiríticas são frequentes e marcam pulsos do magmatismo máfico posteriores ao félsico (Fig. 4). Em seções delgadas a recorrência do magmatismo máfico é caracterizada por texturas de desequilíbrio térmico durante estágios distintos de cristalização das rochas félsicas. Este desequilíbrio é evidenciado através de bordas de reabsorção em quase todas as fases minerais (Fig. 5).

(c) textura rapakivi - em uma porção restrita do BSL, na zona híbrida do corpo, é comum a ocorrência de megacristais de K-feldspato manteados por plagioclásio. Esta textura teve sua origem atribuída a mistura de magmas por Hibbard (1981) (Fig. 6).

(d) trapeamento do magma diorítico - localmente observa-se o aprisionamento do magma de composição diorítica sob o magma de composição quartzo monzonítica a granítica (Fig. 7). Esta feição, que pode ter ocorrido em escala de câmara magmática, justifica um maior período de interação entre os magmas máfico e félsico, favorece a intrusões do magma máfico na câmara magmática félsica em estágios distintos da sua história de cristalização.

Geoquímica do BSL Análises químicas para elementos maiores, traços e terras raras somente foram conduzidas para as litofácies félsica porfirítica (6 amostras) e K-diorítica (3 amostras), predominantes no BSL. As tabelas IA e $1 \mathrm{~B}$ mostram análises químicas de elementos maiores para o BSL.

As amostras são metaluminosas a exceção de duas da fácies félsica porfirítica que são fracamente peraluminosas, com coríndon normativo de 1,08 e $0,60 \%$, respectivamente.

Os óxidos dos elementos maiores plotados contra $\mathrm{SiO} 2$ (diagramas de Harker, (Fig. 8) mostram correlação negativa para $\mathrm{CaO}_{2}, \mathrm{P}_{2} \mathrm{O}_{5}, \mathrm{TiO}_{2}$, $\mathrm{Al}_{2} \mathrm{O}_{3}$ e $\mathrm{Fe}_{2} \mathrm{O}_{3}$. $\mathrm{K}_{2} \mathrm{O}$ e $\mathrm{Na}_{2} \mathrm{O}$ desenvolvem correlação inicial-
Tabela IA-Análises quimicas de elementos maiores para as rochas da fácies félsica porfirítica (monzonitos, quartzo monzonitos, quartzo monzodioritos, granodioritos a granitos) do BSL.

\begin{tabular}{|c|c|c|c|c|c|c|}
\hline Oxido & MSL-16 & MSL-20 & MSL-24 & MSL-32 & MSL-40 & MSL-42 \\
\hline $\mathrm{SiO}_{2}$ & 71,0 & 65,1 & 68,5 & 67,1 & 62,6 & 68,8 \\
\hline $\mathrm{TiO}_{2}$ & 0,42 & 0,87 & 0,57 & 0.56 & 0,87 & 0,51 \\
\hline $\mathrm{Al}_{2} \mathrm{O}_{3}$ & 14,7 & 15,5 & 14,6 & 15,3 & 16,7 & 14,8 \\
\hline $\mathrm{Fe}_{2} \mathrm{O}_{3}$ & 0.59 & 1,2 & 1,4 & 1,1 & 1,3 & 1,2 \\
\hline $\mathrm{FeO}$ & 1,9 & 3.8 & 2,4 & 2,9 & 3.6 & 2,2 \\
\hline $\mathrm{MnO}$ & 0,03 & 0,08 & 0,06 & 0,06 & 0,08 & 0,06 \\
\hline $\mathrm{MgO}$ & 0,57 & 1.40 & 0.78 & 1,10 & 1,30 & 0,80 \\
\hline $\mathrm{CaO}$ & 1,70 & 2,70 & 1.70 & 2,4 & 2,6 & 1,8 \\
\hline $\mathrm{Na} 2 \mathrm{O}$ & 3,5 & 3,8 & 3,9 & 4,0 & 4,2 & 3,8 \\
\hline $\mathrm{K}_{2} \mathrm{O}$ & 4,6 & 4,3 & 5,2 & 4,3 & 5,4 & 4.8 \\
\hline $\mathrm{P}_{2} \mathrm{O}_{5}$ & 0,12 & 0,27 & 0,20 & 0.19 & 0,3 & 0,17 \\
\hline $\mathrm{H}_{2} \mathrm{O}^{+}$ & 0,44 & 0,58 & 0,38 & 0,32 & 0,65 & 0,70 \\
\hline $\mathrm{CO}_{2}$ & 0,05 & 0,13 & 0,05 & 0,26 & 0,17 & 0,11 \\
\hline $\mathrm{H}_{2} \mathrm{O}^{-}$ & 0,27 & 0,18 & 0,26 & 0,16 & 0,24 & 0,20 \\
\hline Total & 99,72 & 99,73 & 99,74 & 99,69 & 99,77 & 99,75 \\
\hline \multicolumn{7}{|c|}{ Constituintes normativos (normas CIPW) } \\
\hline Mineral & MSL-16 & MSL-20 & MSL-24 & MSL-32 & MSL-40 & $\overline{M S L}-42$ \\
\hline$Q$ & 27.70 & 17,38 & 20,54 & 20,02 & 9,09 & 22,79 \\
\hline C & 1,08 & 0,45 &. & 0,59 & 0,14 & 0,61 \\
\hline Or & 27,25 & 25,47 & 30,80 & 25,46 & 31.97 & 29,44 \\
\hline $\mathrm{Ab}$ & 29,61 & 32,15 & 33,00 & 33,84 & 35,54 & 32,15 \\
\hline Di-Di & - & . & . & $\cdot$ & - & - \\
\hline Di-Hd & - & 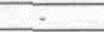 & $\cdot$ & - & - & $\cdot$ \\
\hline $\mathrm{Di}$ & . & . & 0,19 & - & 3,45 & 0,83 \\
\hline Hy-En & - & 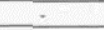 & $=$ & - & 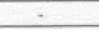 & - \\
\hline $\mathrm{Hy}-\mathrm{Fs}$ & - & - & - & - & $\cdot$ & . \\
\hline Hy & 3,70 & 8,18 & 4.25 & 6,18 & 7.49 & 4,41 \\
\hline $\mathrm{Mt}$ & 1.00 & 1,74 & 2,03 & 1.59 & 1,88 & 1,74 \\
\hline II & 0,80 & 1,65 & 1,08 & 1,25 & 1.65 & 0,97 \\
\hline $\mathrm{Nc}$ & - & - & $\cdot$ & 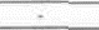 & - & 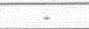 \\
\hline$A p$ & 0,30 & 0,66 & 0,49 & 0,46 & 0.73 & 0,41 \\
\hline $\mathrm{Cc}$ & 0,12 & 0,30 & 0.12 & 0,61 & 0,40 & 0,26 \\
\hline $\mathrm{Zr}$ & 0,05 & 0.08 & 0,08 & 0,07 & 0,09 & 0,06 \\
\hline An & 7,97 & 11,41 & 7,03 & 9,58 & 10,49 & 7,55 \\
\hline
\end{tabular}

Tabela l B - Análises químicas de elementos maiores para as rochas da fácies K-diorítica do BSL (dioritos, biotita dioritos a tonalitos).

\begin{tabular}{|c|c|c|c|}
\hline Óxido & MSL-18 & MSL-19 & MSL-29 \\
\hline $\mathrm{SiO} 2$ & 53,8 & 58,1 & 58,4 \\
\hline $\mathrm{TiO} 2$ & 2,0 & 1,6 & 1,4 \\
\hline $\mathrm{Al} 2 \mathrm{O} 3$ & 17,4 & 16,1 & 17,1 \\
\hline $\mathrm{Fe} 2 \mathrm{O} 3$ & 2,0 & 1,9 & 2,9 \\
\hline $\mathrm{FcO}$ & 6,3 & 5,0 & 4,4 \\
\hline $\mathrm{MnO}$ & 0,09 & 0,11 & 0,11 \\
\hline $\mathrm{MgO}$ & 3,2 & 2,7 & 1,9 \\
\hline $\mathrm{CaO}$ & 6,0 & 4,8 & 4,0 \\
\hline $\mathrm{Na20}$ & 3,7 & 3,9 & 4,0 \\
\hline $\mathrm{K} 2 \mathrm{O}$ & 3,6 & 3,4 & 4,1 \\
\hline $\mathrm{H} 2 \mathrm{O}+$ & 0,5 & 0,66 & 0,66 \\
\hline $\mathrm{H} 2 \mathrm{O}-$ & 0,23 & 0,25 & 0,15 \\
\hline $\mathrm{CO} 2$ & 0,23 & 0,47 & 0,17 \\
\hline $\mathrm{P} 205$ & 0,71 & 0,64 & 0,48 \\
\hline $\mathrm{Total}$ & 99,53 & 99,38 & 99,62 \\
\hline $\mathrm{Constituintcs} \mathrm{normativos} \mathrm{(normas} \mathrm{CIPW)}$ \\
\hline Mineral & $\mathrm{MSL}-18$ & $\mathrm{MSL}-19$ & $\mathrm{MSL}-29$ \\
\hline $\mathrm{Q}$ & 0,94 & 8,72 & 7,90 \\
\hline $\mathrm{C}$ & - & - & 0,11 \\
\hline Or & 21,31 & 20,14 & 24,27 \\
\hline $\mathrm{Ab}$ & 31,31 & 33,00 & 33,84 \\
\hline $\mathrm{Di}$-Di & - & - & - \\
\hline $\mathrm{Di}-\mathrm{Hd}$ & - & - & - \\
\hline $\mathrm{Di}$ & 3,45 & 0,83 & - \\
\hline $\mathrm{Hy}$-En & - & - & - \\
\hline $\mathrm{Hy}$-Fs & - & - & - \\
\hline $\mathrm{Hy}$ & 13,09 & 11,41 & 8,31 \\
\hline $\mathrm{Mt}$ & 2,90 & 2,75 & 4,20 \\
\hline $\mathrm{II}$ & 3,80 & 3,13 & 2,66 \\
\hline $\mathrm{Nc}$ & - & - & - \\
\hline $\mathrm{Ap}$ & 1,71 & 1,55 & 1,16 \\
\hline $\mathrm{Cc}$ & 0,53 & 1,09 & 0,40 \\
\hline $\mathrm{Zr}$ & 0,09 & 0,10 & 0,07 \\
\hline $\mathrm{An}$ & 20,36 & 16,50 & 16,43 \\
\hline
\end{tabular}

mente positiva, caindo levemente para valores de $\mathrm{SiO}_{2}$ acima de $65 \%$. A cristalização tardia de feldspatos pode ser responsável por este comportamento. Os diagramas mostram distribuições lineares a encurvadas, podendo ser interpretadas como decorrentes de processos de mistura de magmas ou cristalização fracionada. É importante ressaltar que mesmo as rochas de composição diorítica do BSL apresentam 


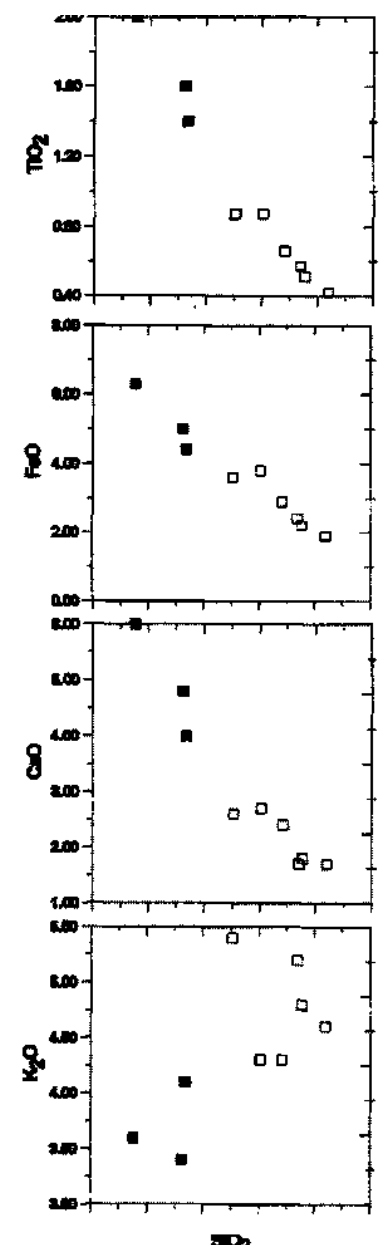

KW IMO n«UU" MOO 7UB

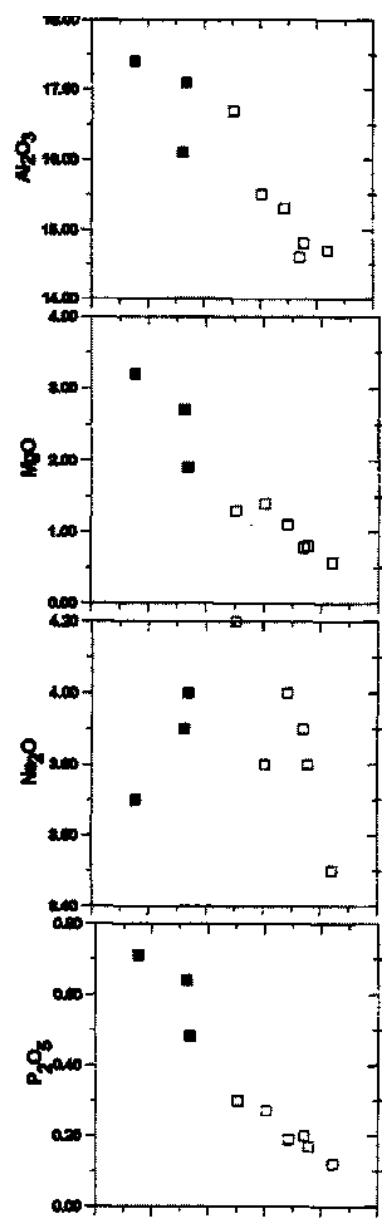

SOOO KOO BUO

UM TOM $7 \mathrm{MO}$

Figura 8- Diagramas de óxidos de elementos maiores vs. $\mathrm{SiO}_{2}$. Quadrados abertos rochas félsicas porfiriticas e quadrados cheios rochas $K$-dioríticas do BSL.

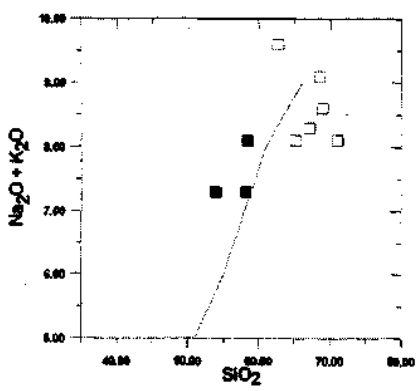

Figura 9 - Diagrama alcalis total vs. $\mathrm{SiO}_{2}$. Linha que separa campos de Irvine \& Baragar (1971). Quadrados abertos - rochas félsicas porfiriticas e quadrados fechados - rochas K-dioríticas do BSL.

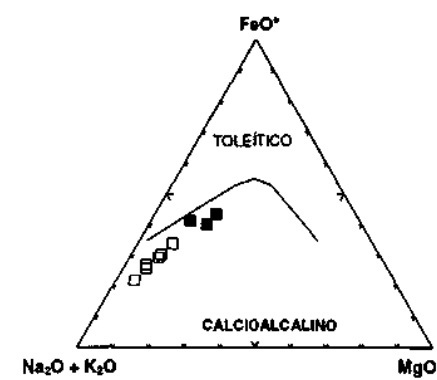

Figura 10 - Diagrama AFM para as rochas do BSL. Quadrados abertos - rochas félsicas porfiriticas e quadrados fechados - rochas K-dioriticas. Linha que divide os campos Irvine \& Baragar (1971).

Tabela $2 A$ - Análises químicas de elementos traços do BSL fácies félsica porfirítica (monzonitos, quartzo monzonitos, quartzo mon-

\begin{tabular}{|c|c|c|c|c|c|c|}
\hline Elemento & MSL-16 & MSL-20 & MSL-24 & MSL-32 & MSL-40 & MSL-42 \\
\hline $\mathrm{Ba}$ & 1580 & 1550 & 1050 & 1390 & 1550 & 1090 \\
\hline $\mathrm{Th}$ & 11 & 9 & 30 & 11 & $<5$ & 16 \\
\hline $\mathrm{Nb}$ & 12 & 23 & 28 & 20 & 30 & 26 \\
\hline $\mathrm{Sr}$ & 610 & 540 & 490 & 550 & 620 & 390 \\
\hline $\mathrm{Rb}$ & 160 & 150 & 170 & 130 & 130 & 190 \\
\hline $\mathrm{Zr}$ & 260 & $\overline{380}$ & 400 & 340 & 470 & 310 \\
\hline $\mathrm{Y}$ & 10 & $\overline{26}$ & 36 & 26 & 36 & 30 \\
\hline
\end{tabular}

Tabela 2B - Análises químicas de elementos traços do BSL, fácies $K$-diorítica (dioritos, biotita dioritos a tonalitos).

\begin{tabular}{|c|c|c|c|}
\hline Elemento & MSL-18 & MSL-19 & MSL-29 \\
\hline $\mathrm{Ba}$ & 2120 & 1980 & 1780 \\
\hline $\mathrm{Th}$ & $<5$ & $<5$ & $<5$ \\
\hline $\mathrm{Nb}$ & 30 & 26 & 29 \\
\hline $\mathrm{Sr}$ & 880 & 960 & 920 \\
\hline $\mathrm{Rb}$ & 92 & 110 & 110 \\
\hline $\mathrm{Zr}$ & 430 & 480 & 340 \\
\hline $\mathrm{Y}$ & 20 & 20 & 27 \\
\hline
\end{tabular}

Tabela $3 A$ - Análises químicas de elementos terras raras do BSL, fácies félsica porfirítica (monzonitos, quartzo monzonitos, granodioritos a granitos.

Tabela 3B-Análises químicas de elementos terras raras para as rochas do BSL, fácies K-dioritica (dioríto, biotita dioritos a tonalitos).

\begin{tabular}{|c|c|c|c|}
\hline Elemento & MSL-18 & MSL-19 & MSL-29 \\
\hline La & 70,47 & 109,20 & 66,51 \\
\hline $\mathrm{Ce}$ & 154,50 & 220,90 & 139,00 \\
\hline $\mathrm{Nd}$ & 67,87 & 86,52 & 57,30 \\
\hline $\mathrm{Sm}$ & 10,35 & 12,47 & 8,93 \\
\hline Eu & 2,00 & 2,15 & 1,75 \\
\hline $\mathrm{Gd}$ & 5,80 & 7,03 & 5,27 \\
\hline $\mathrm{Dy}$ & 3,73 & 3,94 & 3,91 \\
\hline $\mathrm{Hb}$ & 0,72 & 0,75 & 0,78 \\
\hline $\mathrm{Er}$ & 1,84 & 1,87 & 2,10 \\
\hline $\mathrm{Yb}$ & 1,30 & 1,25 & 1,65 \\
\hline $\mathrm{Lu}$ & 0,18 & 0,19 & 0,22 \\
\hline
\end{tabular}

\begin{tabular}{|c|c|c|c|c|c|c|}
\hline Edementio & MSL-16 & MSL-20 & MSL-24 & MSL-32 & MSL-40 & MSL-42 \\
\hline La & $\mathbf{5 3 , 4 9}$ & 66,44 & 60,17 & 59,53 & 61,89 & 55,65 \\
\hline $\mathrm{Ce}$ & 101,70 & $\mathbf{1 2 7 , 8 0}$ & 129,40 & 117,30 & $1,35,60$ & 113,40 \\
\hline $\mathrm{Nd}$ & $\mathbf{3 4 , 7 3}$ & $\mathbf{4 7 , 9 0}$ & 48,85 & 40,80 & 56,78 & 39,80 \\
\hline $\mathrm{Sm}$ & $\mathbf{4 , 5 7}$ & $\mathbf{7 , 3 7}$ & $\mathbf{7 , 6 8}$ & $\mathbf{6 , 2 7}$ & 3,96 & 6,44 \\
\hline $\mathrm{Eu}$ & 1,08 & $\mathbf{1 , 3 0}$ & $\mathbf{1 , 1 6}$ & 1,19 & 1,50 & 1,03 \\
\hline $\mathrm{Gd}$ & 2,75 & $\mathbf{4 , 6 7}$ & 5,19 & 3,93 & 5,45 & 4,22 \\
\hline $\mathrm{Dy}$ & 1,60 & $\mathbf{3 , 5 2 8}$ & 4,05 & 2,90 & 4,27 & 3,68 \\
\hline $\mathrm{Hb}$ & 0,343 & $\mathbf{0 , 7 2}$ & 0,31 & 0,60 & 0,85 & 0,77 \\
\hline $\mathrm{Er}$ & 1,04 & $\mathbf{1 , 9 8}$ & 2,21 & 1,71 & 2,25 & 2,25 \\
\hline $\mathrm{Yb}$ & 1,00 & $\mathbf{1 , 6 0}$ & $\mathbf{1 , 8 1}$ & 1,32 & 1,32 & 1,66 \\
\hline $\mathrm{Lu}$ & $\mathbf{0 , 1 4}$ & $\mathbf{0 , 2 1}$ & 0,23 & 0,21 & 0,24 & 0,26 \\
\hline
\end{tabular}

valores de $\mathrm{K}_{2} \mathrm{O}$ de 3,6 a 4,1 \%, bastante elevados quando comparados com dioritos potássicos na literatura.

No diagrama alcalis totais contra $\mathrm{SiO}_{2}$ (Fig. 9) as amostras félsicas e máficas do BSL mostram uma transição do campo subalcalino para o campo alcalino. Este comportamento independe do teor de $\mathrm{SiO}_{2}$. das amostras e reflete a sua riqueza em alcalis. Trata-se de uma característica comum a todos os plutões cálcio-alcalinos de alto-K da associação tipo-Itaporanga, o que não permite a classificação destas rochas como alcalinas mas evidencia o comportamento peculiar desta associação.

No diagrama AFM (Fig. 10), as amostras do BSL desenvolvem um "trend" no campo cálcio-alcalino, com forte inclinação próximo a linha que une $\mathrm{Na}_{2} \mathrm{O}+\mathrm{K}_{2} \mathrm{O}$ e $\mathrm{FeO}^{*}$, que trata-se de uma característica marcante da associação do tipo-Itaporanga.

Os elementos traços analisados para as rochas do BSL foram Ba, $\mathrm{Th}, \mathrm{Nb}, \mathrm{Sr}$ e $\mathrm{Zr}$ (Tabelas 2A e 2B). Elementos traços plotados contra $\mathrm{SiO}_{2}$ (Fig. 11) mostram o desenvolvimento de trenas retilíneos a ligeiramente curvos, com alguma dispersão. Este comportamento pode ter sido originado por mistura de magmas ou cristalização fracionada, ou, ainda, uma combinação destes processos.

O diagrama multielementar normalizado por rocha basáltica do nordeste do Brasil (Fig. 12) mostra que o K-diorito mais rico em MgO do BSL possui valores normalizados inferiores a três vezes o valor do 
basalto, com vários elementos próximos da unidade, sugerindo afinidade química entre estas rochas.

As amostras analisadas para elementos maiores e traços foram, também, analisadas para elementos terras raras (Tabela 3A e 3B). Os padrões normalizados por condrito são semelhantes para as rochas máficas e félsicas. São caracterizados pelo enriquecimento em terras raras leves em relação aos pesados e anomalia de Eu levemente positiva a inexistente. As rochas de composição diorítica são enriquecidas em terras raras leves em relação as rochas félsicas (Fig. 13).

Geotermometria e geobarometria $A$ utilização de $A 1_{T}$ em anfibólios cálcicos foi proposta como geobarômetro por Hammarstron \& Zen (1983a, 1983b, 1986). Nesses trabalhos os autores discutem uma correlação positiva entre alumínio tetraedral $\left(\mathrm{A} 1^{\mathrm{IN}}\right)$ e alumínio total $\left(\mathrm{A} 1_{\mathrm{T}}\right)$, para as rochas de composição calcio-alcalina. Esta correlacão permite, considerando-se uma assembleia mineral definida, a utilização dos anfibólios como indicadores de sua pressão de cristalização. A comparação das pressões determinadas a partir deste método com aquelas obtidas pelo estudo das assembleias minerais das rochas metamórficas encaixantes, tem demonstrado boa coerência. A equação inicial (Hammarstron \& Zen 1983a) previa erros da ordem de 3,0 kbar, o que limitava a precisão do método. Hollister et al. (1987) redefiniu a equação trazendo o erro para patamares de 1,0 kbar. Johnson \& Rutherford (1989) estudando o equilíbrio líquido + sanidina + plagioclásio $\left(\mathrm{An}_{30}\right)$ + hornblenda + biotita + titanita + ilmenita ou magnetita melhoraram consideravelmente a precisão do método, reduzindo o erro para $0,5 \mathrm{kbar}$

Neste trabalho, devido a concordância entre os dados obtidos através da equação proposta por Hammarstron \& Zen (1983a) e a equação proposta por Hollister et al. (1989), esta foi utilizada para a determinação da pressão de cristalização de anfibólios do litofácies félsica porfirítica do BSL, obtendo-se o valor de 4,5 $\pm 1,0 \mathrm{kbar}$.

A ocorrência de anfibólio e plagioclásio em equilíbrio nas rochas da fácies félsica porfirítica permitiu, também, a utilização do geotermômetro proposto por Blundy \& Holland (1990), obtendo-se temperatura em torno de $740^{\circ} \mathrm{C}$. Os dados de geotermometria e geobarometria permitiram a determinação do gradiente geotérmico para a área de aproximadamente $55^{\circ} \mathrm{C} / \mathrm{km}$.

Isótopos de oxigénio Isótopos de oxigénio para rocha total e para quartzo das rochas félsicas porfiríticas foram determinados no Laboratório de Isótopos Estáveis (LABISE) da UFPE. A extracão de $\mathrm{CO}_{2}$ foi feita em linha de flúor e a análise isotópica do gás em espectrômetro de massa de fonte gasosa da VG Isotech, equipado com duplo alimentador e coletor triplo. A precisão dos resultados é em torno de $0,1 \%$ o.

Os dados obtidos em rocha total para a litofácies félsica porfirítica apresentaram variação de $\delta \mathrm{O}^{18}$ de $+8,9$ a $+9,3 \%$ osmow, enquanto para o litofácies K-diorítica a variação foi de $\delta \mathrm{O}^{18}+7,3 \mathrm{a}+8,2$ $\%_{\text {osmow }}$ (Tabela 4A). A diferença entre os valores de $\delta \mathrm{O}^{18}$ para as rochas félsicas e máficas estão dentro do intervalo de 1,1 a 1,6 \%o, podendo ser atribuída a equilíbrio isotópico entre magmas de fontes distintas, durante processos de mistura de magmas ou a processos de cristalização fracionada, cuja diferença entre os membros máficos e félsicos não excederia $2 \%$.

Taylor (1968) propôs uma equação de correção de valores de rocha total utilizando-se o quartzo, por tratar-se de um mineral inerte a alterações pós-magmáticas, da seguinte forma $\delta \mathrm{O}^{18} \mathrm{RT}=\delta \mathrm{O}^{18}$ Quartzo -1,2. As análises de quartzo, separado de rochas da fácies félsica porfirítica visaram determinar se os valores obtidos para rocha total tratavam-se de valores magmáticos ou teriam sido afetados por alterações secundárias em determinadas fases minerais (p. ex. feldspatos, biotita). Os valores obtidos para quartzo situaram-se dentro do intervalo $\delta \mathrm{O}^{18}+9,8 \mathrm{a}+10,7 \%$ osvow (Tabela 4B). Aplicando-se a equação de Taylor (1968) para as determinações de quartzo do BSL, os valores corrigidos por quartzo para rocha total ficaram no intervalo de $\delta \mathrm{O}^{18}+8,6$ a $+9,5 \%_{\text {osmow, }}$, i.e., dentro do intervalo de variação determinado para rocha total, sugerindo que estes representam valores magmáticos.

Isótopos radiogênicos Duas amostras da litofácies félsica porfirítica e uma da litofácies diorítica do BSL foram analisadas para Sm-Nd na universidade do Kansas, Estados Unidos, por Ignez de P. Guimarães e Adejardo F. da Silva Filho. As amostras félsicas porfiríticas apresentaram T(DM) de 1,78 e $1,70 \mathrm{Ga}$ e $\varepsilon_{\mathrm{Nd}}(600 \mathrm{ma})$ de $-11,5 \mathrm{e}$ -10,2. A amostra de K-diorito apresentou T(DM) de 1,78 Ga e $\varepsilon_{\mathrm{Nd}}(600 \mathrm{ma})$ de $-11,5$. Estas idades modelos sugerem que a fonte do BSL foi formada essencialmente durante o ciclo Transamazônica (ca

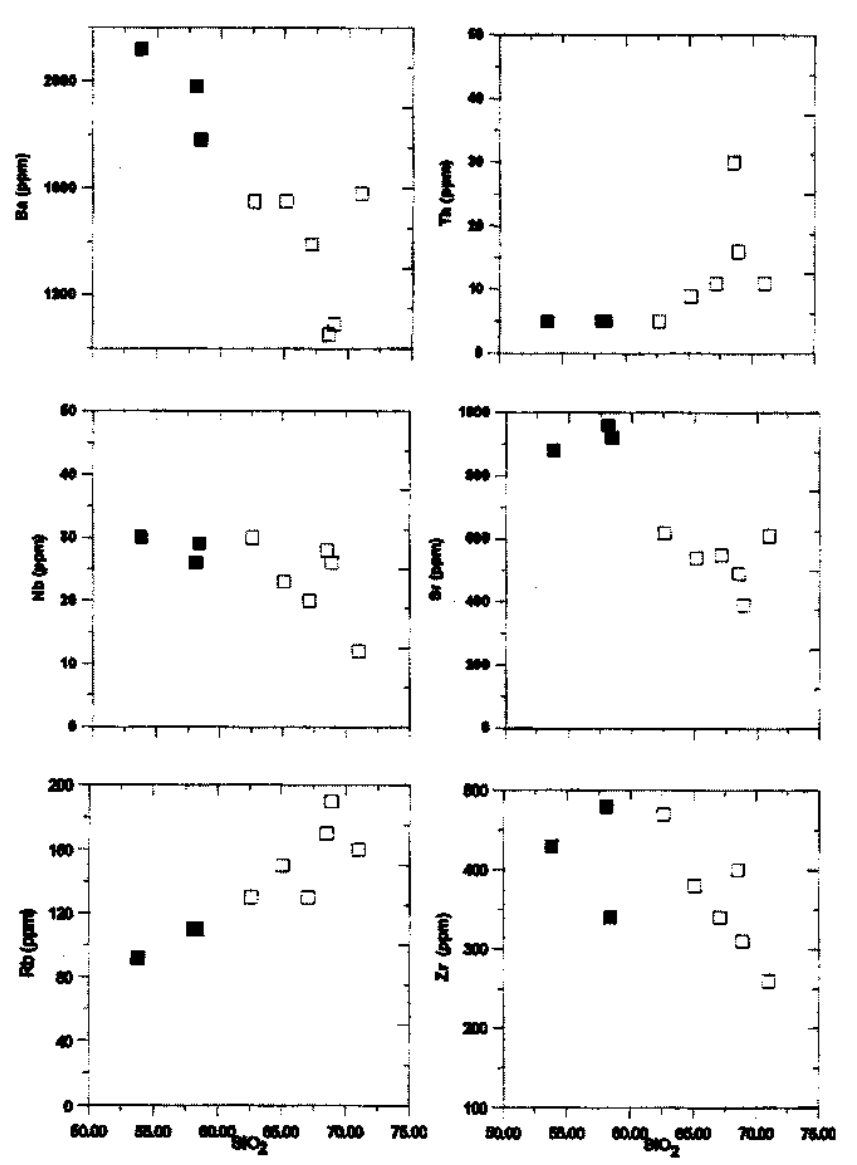

Figura 11 - Elementos traços vs. SiO2. Quadrados abertos - rochas félsicas porfiriticas e quadrados fechados - rochas $K$-dioríticas do BSL.

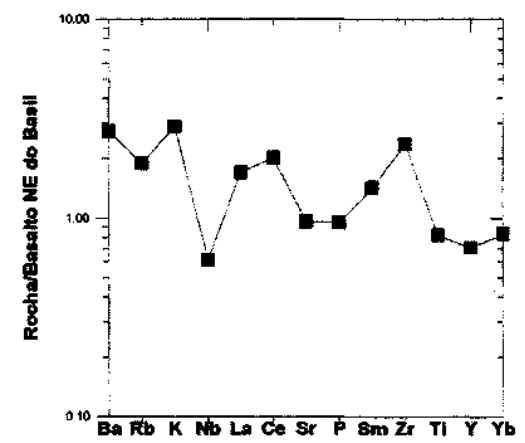

Figura 12 - K-diorito do BSL normalizado por Basaltos do Nordeste do Brasil. F atares de normalização Sial et al. (1991).

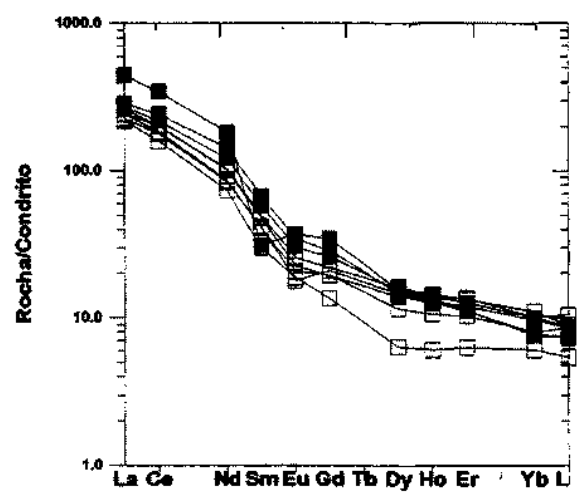

Figura 13 - Elementos terra raras normalizados por condrito. Fatores de normalização de Evensen et al. (1978). Quadrados abertos - rochas félsicas porfiriticas e quadrados fechados - rochas $K$-dioríticas. 
Tabela $4 A$ - Isótopos de oxigénio em rocha total do BSL.

\begin{tabular}{|c|c|c|}
\hline \multicolumn{3}{|c|}{$\begin{array}{l}\text { a) Litoficies félsico portirítico (monzonitos, quartzo monzonitos, quartzo monzodioritos, } \\
\text { granodioritos a granitos). }\end{array}$} \\
\hline AMOSTRA & $8^{180(\% 0)}$ & COMPOSIÇÄO MODAL \\
\hline $\mathrm{msl}-32$ & $+9,3$ & quartzo monzonito \\
\hline $\mathrm{msl}-20$ & $+8,9$ & quarzo monzonito \\
\hline \multicolumn{3}{|c|}{ b) Litofacies K-dioritico (dioritos, biotita (quartzo) dioritos a tonalitos) } \\
\hline AMOSTRA & $\delta^{18} O(\% \circ)$ & COMPOSIÇÃOMODAL \\
\hline msl-18 & $+7,3$ & quartzo diorito \\
\hline $\mathrm{msl}-19$ & $+8,2$ & guanzo diorito \\
\hline msl-29 & $+8,1$ & monzodiorito \\
\hline
\end{tabular}

Tabela $4 B$ - Isótopos de oxigénio em quartzo e valores corrigidos por quartzo para o BSL.

\begin{tabular}{|c|c|c|c|}
\hline AMOSTRA & $\delta^{18} \mathrm{O}(\% 0)$ & $\delta^{18} \mathrm{O}(\% 0)^{*}$ & COMPOSIÇÁ MODAL \\
\hline $\mathrm{msl}-16$ & $+10,75$ & $+9,55$ & granito \\
\hline $\mathrm{ms} \mathrm{l}-24$ & $+10,34$ & $+9,14$ & quartzo monzodiorito \\
\hline $\mathrm{mss}-32$ & $+9,84$ & $+8,64$ & quartzo monzodjorito \\
\hline $\mathrm{ms} l-42$ & $+10,67$ & $+9,47$ & quartzo monzodiorito \\
\hline
\end{tabular}

Legenda: * = valores de rocha total corrigidos por quartzo pela equação:

$\delta^{18} \mathrm{O}_{\mathrm{RT}}=\delta^{18}$ Oquartzo- 1.2

1,9 a 2,0 Ga), podendo ter sofrido uma pequena contribuição de rochas de idade Cariris Velhos (ca 0,9 a $1,0 \mathrm{Ga}$ ).

DISCUSSÃO E CONCLUSÕES Coexistência e mistura de magmas EVIDENCIAS DE CAMPO As evidências de campo (Figs. 3,4 e 7) são fortes argumentos em favor da coexistência e mistura de um magma de composição diorítica rico em $\mathrm{K}_{2} \mathrm{O}$ com um magma de composição quartzo monzonítica a granítica, também, rico em $\mathrm{K}_{2} \mathrm{O}$, além de caracterizarem a recorrência do magmatismo $\mathrm{K}$ diorítico. Estruturas tipo estromática (Fig. 3) com origem magmática, isto é, sem o concurso de tectônica, ilustram a relação comagmática entre os magmas máfico e félsico, reforçada pela migração de megacristais de K-feldspato das bandas félsicas para as máficas e sua ocorrência truncando os contatos entre estas bandas. Diques de composição diorítica truncando a rocha félsica porfirítica e livres de megacristais de K-feldspato (Fig. 4), mostram que pulsos do magma máfico ocorreram após a cristalização total das rochas félsicas. Desta forma, a interação entre os magmas máfico e félsico no BSL se deu em, pelo menos, dois eventos magmáticos.

Bordas de reabsorção em quase todas as fases minerais das rochas híbridas (quartzo dioritos a quartzo monzonitos; (Fig. 5) são o registro da quebra de equilíbrio entre as fases minerais neoformadas e o líquido residual, causado pelo aumento de temperatura quando da recorrência de pulsos do magmatismo máfico.

A multiplicidade de pulsos do magma máfico durante a evolução do BSL pode ser explicada pelo aprisionamento de magma diorítico na base da câmara magmática félsica (Fig. 7). A retenção do magma diorítico na base da câmara magmática félsica favoreceu, além da recorrência do magmatismo máfico, intensa interação entre estes magmas, promovendo extensiva hibridização.

GEOQUIMICA Diagramas para elementos maiores e traços vs. $\mathrm{SiO}_{2}$ para o BSL (Figs. 8 e 12) mostram distribuições lineares ou próximas à linearidade, que podem ser explicadas por processos de mistura de magmas de fontes distintas ou por cristalização fracionada a partir de uma magma comum.

Os valores de isótopos de oxigénio em rocha total obtidos para as rochas máficas $(\mathrm{S} \mathrm{O}=+7,9 \%$ osmow $)$ e félsicas $\left(6 \mathrm{O}^{18}=+9,1\right.$ $\%_{\text {osmow }}$ ) refletem a natureza híbrida das mesmas e não afastam a possibilidade dos dois magmas terem sido originados da mesma fonte e evoluído a partir de cristalização fracionada ou de terem fontes distintas, embora semelhantes, que interagiram durante o estágio magmático.

$\mathrm{O}$ enriquecimento em elementos terras raras leves nas rochas de composição diorítica em relação às rochas félsicas porfiríticas (Fig. 13), representa a evidência geoquímica mais forte contra a importância do processo de cristalização fracionada no BSL, uma vez que os elementos terras raras leves são incompatíveis e tendem a se concentrar, durante a cristalização fracionada, nos membros mais diferenciados. Na figura 14, diagrama Ce vs. Yb, torna-se claro que os trenas desenvolvidos para as rochas dioríticas e para as rochas félsicas porfiríticas são distintos. A redução em $\mathrm{MgO}$, valores em negrito acima dos símbolos, para as rochas dioríticas e quartzo monzoníticas a

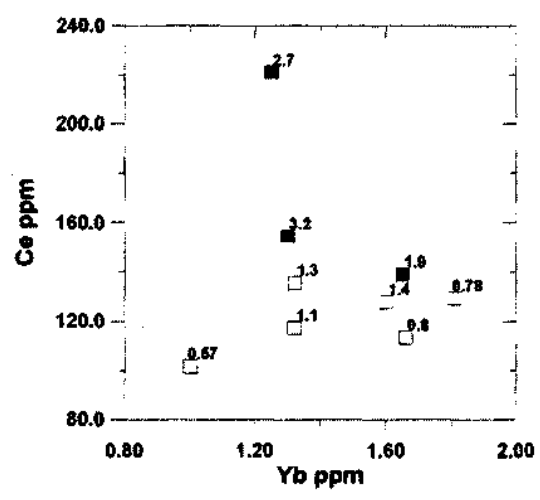

Figura 14 - Ce vs. Yb. Quadrados abertos - rochas fé Is iças porfiríticas e quadrados fechados - rochas K-dioriticas.

Tabela 5 - Relação de coeficientes de distribuição para plagioclásio, hornblenda, apatita para magmas de composição granitica. Fonte Watson \& Capobianco 1981

\begin{tabular}{|l|l|l|l|}
\hline Elemento & \multicolumn{3}{|l|}{ coeficientes de partiçó mineral/líquido } \\
\hline & plagioclásio & hornblenda & apatita \\
\hline $\mathrm{Ce}$ & 0.27 & 1.5 & 35 \\
\hline $\mathrm{Sm}$ & 0.14 & 7.5 & 60 \\
\hline $\mathrm{Dy}$ & 0.065 & 13.0 & 50 \\
\hline $\mathrm{Yb}$ & 0.05 & 8.0 & 21 \\
\hline
\end{tabular}

graníticas resultam em trenas evolutivos completamente distintos inviabilizando a evolução magmática de dioritos para quartzo monzonitos a granitos, no BSL, através do processo de cristalização fracionada. O diagram Ce vs. Yb torna claro que os magmas máfico e félsico do BSL tiveram fontes distintas e interagiram através do processo de mistura de magmas. Por outro lado, o processo de cristalização fracionada pode ter ocorrido, em pequena escala, entre as rochas de composição diorítica e entre as rochas de composição quartzo monzonítica a granítica de forma independente.

Cristalização fracionada nos dioritos Considerando que durante o fracionamento do magma ocorre uma redução em $\mathrm{MgO}$ nos membros mais diferenciados, observa-se que para as rochas dioríticas a redução de $\mathrm{MgO}$ de 3,2 para 1,9 \%, implica em uma redução de $\mathrm{Ce}, \mathrm{Sm}$ e aumento de Dy e Yb. As razões entre o mais fracionado (MSL29) e o menos fracionado (MSL 18) para Ce, Sm, Dy, e Yb são, respectivamente, 0,$89 ; 0,86 ; 1,04$ e 1,26 . De acordo com este comportamento fases que em conjunto possuíssem DSm $>\mathrm{DCe}>\mathrm{DDy}>\mathrm{DYb}$ deveriam estar sendo fracionadas. A tabela 5 mostra a distribuição de Kd para alguns minerais para líquido de composição granítica (Watson \& Capobianco 1981). O fracionamento de apatita implicaria em $\mathrm{KdSm}>\mathrm{KdDy}>\mathrm{KdCe}>\mathrm{KdYb}$, que não corresponde ao observado. A possibilidade do fracionamento conjunto de apatita, associada a fases maiores como plagioclásio e anfibólio poderia derivar o comportamento observado. Todavia este fracionamento poderia ter como resultado uma variação composicional mais ampla do que a observada para as rochas máficas do BSL.

\section{Cristalização fracionada nas rochas félsicas porfiríticas}

Para as rochas félsicas a redução de $\mathrm{MgO}$ de 1,4 para $0,67 \%$ em peso, corresponde a uma redução em Dy, Sm, Yb, e Ce. As razões entre a rocha mais fracionada (MSL 16) e a menos fracionada (MSL 20) para Dy, Sm, Yb e Ce são, respectivamente 0,$45 ; 0,62 ; 0,62$ e 0,79 . De acordo com este comportamento, fases que resultassem em DDy> $\mathrm{DSm}=\mathrm{Dyb}>$ Dce estariam envolvidas nos estágios iniciais de fracionamento. Observando-se a Tabela 5 nota-se que hornblenda tem coeficientes de distribuição para estes elementos que satisfazem a observacão acima, i.e. KdDy $>\mathrm{KdSm} \sim \mathrm{KdYb}>\mathrm{KdCe}$. Os estudos petrográficos desta fácies mostram a cristalização de hornblenda como uma das fases iniciais sugerindo a possibilidade de fracionamento cedo de anfibólio como responsável pelo trend definido na figura 14 para as rochas félsicas.

Isótopos radiogênicos -possíveis fontes Dados de $\mathrm{Sm}-\mathrm{Nd}$ revelam idade modelo para a fonte das rochas félsica (duas amostras) entre 1,70 e $1,78 \mathrm{Ga}$, com $\mathrm{e}_{\mathrm{Nd}}(600 \mathrm{ma})$ entre $-11,5$ e $-10,2$ e para uma 
amostra máfica em torno de $1,78 \mathrm{Ga}$ e $\varepsilon_{\mathrm{Nd}}(600 \mathrm{ma})$ de -11,5. Esta concordância nas idades modelos das rochas máficas e félsicas e os valores extremamente negativos de $\varepsilon_{\mathrm{Nd}}$ reforçam a ideia de um manto litosférico enriquecido como fonte do magmatismo potássico da associação cálcio-alcalino no nordeste do Brasil, como já proposto por Neves \& Mariano (1997). O enriquecimento em potássio, especialmente das rochas dioríticas, associado ao enriquecimento em elementos incompatíveis apontam para uma fonte mantélica metassomatizada enquanto que a geoquímica das rochas félsicas sugere um forte componente mantélico, semelhante aos K-dioritos menos diferenciados (Neves \& Mariano 1997). Esta semelhança composicional associado a multiplicidade dos pulsos de magmas de composição K-dioritica favoreceu a atuação do processo de mistura de magmas no BSL e, de maneira geral, em todos os corpos da associação calcio-alcalina de alto-K do nordeste do Brasil. De acordo com os dados de Sm-Nd o evento metassomático do manto sob o Nordeste do Brasil dataria de, pelo menos, 2,0 Ga (Ciclo Transamazônico).

Agradecimentos Este trabalho foi parcialmente financiado por projeto do PADCT coordenado pelo Prof. Alcides Nobrega Sial e por projeto da FACEPE, coordenado pelo Prof. Gorki Mariano, tendo sido desenvolvido como dissertação de mestrado por Maurício de Nassau de Mattos Sobreira. As análises de Sm-Nd foram realizadas pela Prof. Ignez de Pinho Guimarães e Adejardo F. da Silva Filho, a quem expressamos a nossa gratidão. Dois revisores anónimos contribuíam de forma significante para o aprimoramento da versão final do trabalho.

\section{Referências}

Almeida, F.F.M. de; Leonardos O. H.; Valença, Jr.,1967. Granitic rocks of northeastern South America. Recife, IUGS/UNESCO,41p.

Blundy, J.D Holland T.J.B. 1990. Calcic amphibole equilibria and a new amphibole-plagioclase geothermometer. Contrib. Mineral Petrol. 104:208-224.

Brito Neves, B. B. de 1975. Regionalização geotectônica do Pre-Cambriano nordestino. Inst. de Geociências, Universidade de São Paulo Tese de Doutoramento, 198p.

Brito Neves, B. B. de; Schmus, V.; Santos; E. F. dos; Campos Neto, M. C.; Kozuch, M. 1996. O evento Carirís Velhos na província Borborema: integração de dados, perspectivas e implicações. In: SBG Congresso Brasileiro de Geologia ,39, Salvador, Anais, 6:19-22.

Ebert, H. 1962. Bastil and regional metamorphism in Prekambrischen grundgeberge brasileins. Tschermarks Min. U. Petr. Mitt. 8:49-81.

Evensen, N. M.; Hamilton, P. J.; O'Nions, R. K. 1978. Rareearth abundances in chondritic meteorites. Geochim. Cosmochim. Acta, 42:1199-1212.

Hammarstrom, J. M. \& Zen E. 1986. Aluminum in hornblende: An empirical igneous geobarometer. Amer. Mineral., 72:1297-1313.

Hammarstrom, J. M. \& Zen, E. 1983a. An empirical equation for igneous calcic anphibole geobarometry. Geol. Soe. Amer. Abstracts with Programs, 17:602.

Hammarstrom, J. M. \& Zen, E. 1983b. Possible use of Al content in hornblende as a geobarometer for plutonic rocks. Geol. Soe. Amer. Abstracts With Programs, 15:590

Hibbard, M. J. 1981. The magma mixing origin of mantled feldspars. Contrib. Mineral. Petrol. 76:188-170

Hogan, P. J. 1993 Monomineralic glomerocrists: textural evidence for mineral reabsortion during crystallization of igneous rocks. Journal of Geol. 101:531-540.

Hollister, L. S.; Grissom, G. C.; Petters, E. K.; Stowell, H.H.; Sisson, V.B. 1987. Confirmation of the empirical correlation of $\mathrm{Al}$ in hornblende with pressure of solidification of calc-alkaline plutons. Amer. Mineral., 72 :231-239.

Irvine, T. N. \&Baragar, W. R. A. 1971. A guide do chemical classification of the common volcnic rocks. Canadian Jour. Earth Sei 8.523-548.

Jardim de Sá, E. F. 1994. A faixa Seridó (Província Borborema, NE do Brasil) e o seu significado geodinâmica na cadeia Brasiliana/Pan-Africana. UnB. Tese de Doutorado, Brasília, $803 \mathrm{p}$

Johnson, M.C. \& Rutherford, M.J. 1989. Experimental calibration of the aluminium in hornblende geobarometro with application to long valley caldera (Califórnia) volcanic rocks. Geology,. 17:837-843.

Leake, B.E.; Wolley, A. R.; Arps, C. E. S.; Birch, W. D.; Gilbert, M. C.; Grice, J. D. Hawthorne, F. C.; Kato, A; Kish, H. J.; Krivovichev, V. G.; Linthouth, K.; Laird, J.; Mandarino, J. A.; Maresch, W. V.; Nickel, E. H. Rock, N. M. S.; Schumaher, J. C.; Smith, D. C.; Stephenson, N. C. N.; Ungarettí, L.; Whittaker, J. W.; Youzh, G. 1997. Nomenclature of amphiboles: report of the subcomittee on amphiboles of the international mineralogical association, commission on new minerais and mineral names.. American Mineralogist 82:1019-1037.

Mariano, G. \& Sial, A. N. 1990. Coexistence and mixing of magmas in the Late Precambrian Itaporanga batholith, state of Paraíba, northeastern Brazil. Rev. Brás. Geoc. 20 (1-4): 101-1 10

Mariano, G. 1989. Magma mixing origin of a high K-calc-alkaline pluton: the Itaporanga-type bathilith, state of Paraiba, northeastern Braszil. Departmento de Geologia, Universidade da Georgia, Athens, Georgia, USA Tese de Doutoramento, $180 \mathrm{p}$.

Mariano, G. 1994. Petrographic evidence for coexistence and interaction berween magmas of contrasting composition: o Serra da lagoinha batholith, state of Paraíba, northeastern Brazil. In: SBG Congresso Brasileiro de Geologia, 38 Camboriú, Boletim de Resumos Expandidos 1:173-174.
Mariano, G.; Sial, A. N.; Long, L. E. 1992. The Itaporanga-type association in northeast Brasil: a case of magma mixing. In: Intern. Geol. Congress 29, Kyoto, Japan 1991 Atas... JapanIUGSp. 517.

McMurry, J. 1991. Petrology and geocchemistry of a megacrystic quartz monzonite: the Bodocó pluton, NE Brazil. Ph.D. Dissertation. Texas Tech University. 256p.

Neves, S. P. \& Mariano, G. 1997. High-K calc-alkalic plutons in northeast Brazil: origin of the biotite diorite/quartz monzonite to granite association and implications for the evolution of Borborema Province. International Geology Review 39(I): $621-638$.

Neves, S. P. \& Vauchez, A. 1995. Successi ve mixing and mingling of magmas in a plutonic comple of northeast Brazil. Lithos, 34:275-299.

Neves, S. P. 1996. Étude dês relations entre magmatism et zones de cisaillement lithosphériques: exemple dês décrochement de Pernambuco et Fazenda Nova Etat de PErnambuco-Brésil. Tese de Doutorado, Universidade de Montpellier II, França de PE
$241 \mathrm{p}$.

Neves, S. P.; Vauchez, A.; Archanjo, C. J. 1996. Shear zone-controlled magma emplacement or magma assisted nucleation of shear zones? Insights from norteastern Brasil. Tectonophysics. 262:349-364.

Santos, E. J. dos 1995. O complexo granítico Lagoa das Pedras: acresção e colisão na região de floresta (Pernambuco), Província Borborema. USP/IG. Tese de Doutorado, 219p.

Sial, A. N.; Lima, E. S.; Pessoa, D. A.; Castro, C.; Villaroel, H. S.; Rodrigues da Silva, M. R.;, Borba, G.S.; Lima, G. R. 1981a. Petrologia e geoquímica do batólito de Bodocó e stocks de Serrita Pernambuco./n: SBG, simpósio de Geologia do Nordeste 10, Recife. Atas, 338-401.

Sial, A. N.; Lima, E. S.; Pessoa, D. A.; Castro, C.; Villaroel, H. S.; Rodrigues da Silva, M. R.; Borba, G.S.; Lima, G. R. 1981b. Geoquímica de dois stocks granodioríticos de Serrita (PE): Elementos maiores. Univ. Fed. de Pernambuco. Dept. de Geologia, Estudos e Pesquisas, 4:27-52.

Sial, A. N.; Mariano, G.; Ferreira, V. P. 1989. Isotope geochemistry of Brasiliano-age, coarsely porphyritic, K-calc-alkalic and associated K-diorites, northeastern Brasil In: SBGq. Congresso Brasileiro Geoquímica 2, Rio de Janeiro, Anais, 229-240.

Sial, A. N.; Fodor, R. V.; Long, L.E. 1991.Peridotitexenoliths and tertiary alkaline basalts in northeastern Brazil. In: Fith International Kimberlite Conferense -Núcleo de Edičões Técnicas - CPRM. Rio de Janeiro 3-13.

Sobreir MNM. (1995) Obatólito potássico cálcio-alcalino de Serra da Lagoinha estado da Paraiba, nordeste do Brasil: petrologia e geoquímica. Dissertação de mestrado, pó s-graduação em Geociências, UFPE, 95p.

Sobreira, M.N.M.; Mariano, G.; Sial A. N. 1993. O batólito cálcio-alcalino de Serra da Lagoinha, estado do Paraíba. In: SBG.Núcleo Nordeste XIVSimpósio de Geologia do Nordeste, Natal, 13:97-100.

Streckeisen, A.L. 1976. Classification of the common igneous rocks means of their chemical composition - a provisional attempt. Newes Jahrbuch fur Mineralogic Monatshefte, 1-15.

Taylor, H. P. Jr. 1968. The oxygen isotope geochemistry of igneous rocks.. Contrib. Mineral Petrol. ,19:1-17.

Watson, E.B. \& Capobianco, C. J. 1981. Phosphorous and the rare earth elements in felsic magmas: na assessment of the role of apatite. Geochem. Cosmochem. Acta. 45:2349-2358

Manuscrito A-1022 